OPEN ACCESS

Edited by:

Jinxing Lin,

Beijing Forestry University, China

Reviewed by:

Qinghua Wang,

University of Toronto, Canada

Eva Darko,

Hungarian Academy of Sciences

(MTA), Hungary

*Correspondence:

Yan Peng

pengyanlee@163.com

${ }^{\dagger}$ These authors have contributed equally to this work.

Specialty section:

This article was submitted to

Plant Physiology,

a section of the journal

Frontiers in Physiology

Received: 26 August 2017 Accepted: 14 December 2017 Published: 22 December 2017

Citation:

Yong B, Xie H, Li Z, Li Y-P, Zhang Y, Nie G, Zhang $X-Q$, Ma X, Huang $L-K$,

Yan Y-H and Peng Y (2017)

Exogenous Application of GABA

Improves PEG-Induced Drought

Tolerance Positively Associated with GABA-Shunt, Polyamines, and Proline

Metabolism in White Clover.

Front. Physiol. 8:1107.

doi: 10.3389/fphys.2017.01107

\section{Exogenous Application of GABA Improves PEG-Induced Drought Tolerance Positively Associated with GABA-Shunt, Polyamines, and Proline Metabolism in White Clover}

\author{
Bin Yong ${ }^{1+}$, Huan Xie ${ }^{1,2+}$, Zhou $\mathrm{Li}^{1}$, Ya-Ping $\mathrm{Li}^{1}$, Yan Zhang ${ }^{1}$, Gang Nie ${ }^{1}$, Xin-Quan Zhang ${ }^{1}$, \\ Xiao Ma ${ }^{1}$, Lin-Kai Huang ${ }^{1}$, Yan-Hong Yan ${ }^{1}$ and Yan Peng ${ }^{1 *}$ \\ ${ }^{1}$ Department of Grassland Science, Animal Science and Technology College, Sichuan Agricultural University, Chengdu, \\ China, ${ }^{2}$ Ganzi Prefecture Grassland Station of Sichuan Province, Kangding, China
}

In order to investigate the physiological effects of exogenous $\gamma$-aminobutyric acid (GABA) on drought tolerance in white clover (Trifolium repens), GABA shunt, polyamines (PAs), and proline (Pro) metabolism were examined after plants pretreated with or without GABA (8 mM) and then exposed to water or 15\% PEG-induced drought stress in growth chamber. In this study, exogenous application of GABA effectively alleviated drought-induced damage in leaves, as reflected by significantly higher relative water content, lower electrolyte leakage, lipid peroxidation, and leaf wilt. Exogenous GABA further promoted drought-induced increases in GABA transaminase and alpha ketone glutarate dehydrogenase activities, but inhibited glutamate decarboxylase activity under both control and drought conditions, resulting in an increase in endogenous glutamate (Glu) and GABA content. Besides, exogenous GABA could well accelerated PAs synthesis and suppressed PAs catabolism, which lead to the extremely enhanced different types of PAs content (free Put and Spd, insoluble bound Spd and Spm, soluble conjugated Spd and Spm, and total Put, Spd and Spm) under drought stress. In addition, exogenous GABA application further activated drought-induced $\Delta^{1}$-pyrroline-5-carboxylate synthetase and proline dehydrogenase activities, but suppressed drought-facilitated ornithine $-\delta$-amino transferase activities, leading to a higher Pro accumulation and metabolism in GABA-pretreated plants in the middle and last period of drought. The results suggested that increased endogenous GABA by exogenous GABA treatment could improve drought tolerance of white clover associated with a positive regulation in the GABA-shunt, PAs and Pro metabolism.

Keywords: $\gamma$-aminobutyric acid, polyamines metabolism, proline accumulation, drought stress, white clover

\section{INTRODUCTION}

Drought stress is one of the most severe limiting factors that negatively affects plant growth and development in perennial forage species around the world (Annicchiarico and Piano, 2004). The scarcity of available water restrains plant productivity due to drought-induced cellular membrane damage, nutritional imbalance, and metabolic disorders. However, plants have evolved a range 
of physiological, biochemical, and metabolic responses to drought stress including the synthesis or degradation of phytohormone, plant growth regulators (PGRs), osmolytes, and antioxidants defense associated with drought tolerance. Recently, the exogenous application of PGRs is an effective strategy to alleviate drought damage in plant, such as glutamic (Glu), proline (Pro), polyamines (Pas; Yamaguchi et al., 2007; Li et al., 2016b) and $\gamma$-aminobutyric acid (GABA; Hu et al., 2015). GABA is a four-carbon non-protein amino acid which could rapidly accumulate when plants suffer from environment stresses (Bown and Shelp, 1997; Medina et al., 2009; Narsai et al., 2011). The biosynthesis of endogenous GABA is mainly involved in two pathways: one is the decarboxylation of Glu from the catalytic action of glutamate decarboxylase (GAD) in the cytosol and the other was from the degradation of PAs through diamine oxidase $(\mathrm{CuAO})$ and polyamine oxidase (PAO) (Bhatnagar et al., 2001).

In recent years, more and more studies have indicated that GABA plays a special role in the regulation of the tolerance to abiotic stress in plants rather than just a metabolite. It had been widely demonstrated that exogenous application of GABA successfully enhanced the tolerance to various abiotic stresses in plants. It was reported that exogenous application of GABA positively regulated the antioxidant defense and photosynthesis in pepper (Capsicum annuum) seedlings under low light stress ( $\mathrm{Li}$ et al., 2017). Also, GABA pre-treating could alleviate the damage induced by chilling stress in tomato (Lycopersicon esculentum) seedling, peach (Primus persica) fruit as well as wheat (Triticum aestivum) seedlings (Shang et al., 2011; Al-Quraan et al., 2013; Malekzadeh et al., 2014). GABA-treated rice (Oryza sativa) suffered less heat stress due to the accumulation of increased osmolytes and the up-regulation of antioxidant ability (Nayyar et al., 2013). What's more, exogenous GABA improved the resistance to saline-alkaline in muskmelon (Cucumis melon) involved in the protection of photosynthesis apparatus and the alleviation of stress-related photoinhibition (Xiang et al., 2016). For the drought stress, Vijayakumari and Puthur (2015) indicated that GABA application could significantly enhance the drought tolerance through alleviating lipid peroxidation and inhibiting photosynthetic and mitochondrial activity in black pepper (Piper nigrum). In addition, application of exogenous GABA also improved drought resistance of creeping bentgrass (Agrostis stolonifera) associated with the increased accumulation of amino acids, organic acids, and other osmotic substances related to secondary metabolism (Li et al., 2016a). Moreover, it is proved that the reduction of GABA content closely in relation to a decreased resistance to drought in Arabidopsis mutant by the knock-out of glutamate decarboxylase gene (Mekonnen et al., 2016). In conclusion, it is suggested that GABA plays a positive role in physiological modulation when plants suffer from unfavorable environment stresses and the manipulation of GABA levels could be a potential method in enhancing stress resistance in plants.

In plants, GABA shunt exhibits particular roles in the maintenance of carbon/nitrogen balance, regulation of cytosolic $\mathrm{pH}$, scavenging of reactive oxygen species, osmoregulation, and signaling transduction coupling with TCA cycle (Serraj et al., 1998; Bouché and Fromm, 2004; Shi et al., 2010; Krishnan et al., 2013; Mekonnen et al., 2016). In GABA shunt, owing to the loss of GABA transaminase (GABA-T) in Arabidopsis pop2 mutant lines, Arabidopsis generally showed more sensitive to various abiotic stresses (Al-Quraan and Al-Share, 2015). Moreover, the functions of GABA closely linked with PAs and Pro in plants when response to abiotic stress. The catabolism of PAs is an important origin of GABA production and Pro shares the common synthetic precursor glutamic acid with GABA. Hu et al. (2015) demonstrated that exogenous GABA application positively facilitated PA biosynthesis and enhanced endogenous GABA level, which effectively alleviated $\mathrm{Ca}\left(\mathrm{NO}_{3}\right)_{2}$ stress damage in muskmelon. Shang et al. (2011) proposed that GABA treatment could well accumulate the content of endogenous GABA and proline, which was useful to protect peach fruit suffering from chilling injury. However, these researches only partly illustrate probable relationships between GABA and other PGRs (Glu, PAs, or Pro), it is still scarce about a comprehensive understanding of the effects of exogenous GABA on GABA shunt, PAs, and Pro metabolic pathways when plants encountered abiotic stress.

White clover (Trifolium repens) is an important cool-season forage and turfgrass, which has been widely planted in grassland and landscaping owing to its high crude protein content, nitrogen fixation ability, and excellent ornamental characteristics. However, white clover is very sensitive to limited water supply in production (Annicchiarico and Piano, 2004; Mercer and Watson, 2007). Therefore, it is critical for increasing the drought resistance of white clover through economic and effective strategy. In this study, white clover "Ladino" was pretreated with exogenous GABA in roots before exposed to Polyethylene glycol (PEG, a widely used drought inducer similar to natural water shortage in plants) induced drought stress (Fan and Blake, 1997; Comeau et al., 2010; Kautz et al., 2015). The objectives were (1) to examine whether application of exogenous GABA could alleviate drought damages, (2) to assess the effects of exogenous GABA on GABA shunt, polyamines, and proline metabolic pathway. Such information will be benefited to better understand the physiological adaptability to environmental stress in plants and develop effective cultivation measures to protecting plants from drought stress.

\section{MATERIALS AND METHODS}

\section{Plant Materials Culture}

The same size and grain plumpness seeds of white clover cv. "Ladino" were selected in this study and all seeds were sterilized with $0.1 \% \mathrm{HgCl}_{2}$ for $3 \mathrm{~min}$ and then rinsed 3 times with distilled water. $0.1 \mathrm{~g}$ seeds were sown in each seedlings tray $(24 \mathrm{~cm}$ length, $20 \mathrm{~cm}$ width and $15 \mathrm{~cm}$ deep) with pre-sterilized quartz sand and then placed all trays in growth chamber (16 h photoperiod, $75 \%$ relative humidity, and $23 / 19^{\circ} \mathrm{C}$ day/night) with distilled water for germination 7 days. In subsequent stage, the seedlings were watered with fresh Hoagland's solution (Hoagland and Arnon, 1950) in roots every 2 days.

\section{GABA Pretreatment and Drought Stress}

After 30 days (the second leaves fully expanded), the plants were exposed to four treatments: (1) Control (well watering plants with Hoagland's solution in roots); (2) GABA (pretreating plants for 4 
days with $8 \mathrm{mM}$ GABA in roots, watering GABA solution once every 2 days); (3) PEG [watering 15\% PEG-6000 (W/V) solution in roots]; (4) GABA+PEG (pretreating the plants with GABA as treatment (2) before PEG treatment). Three hundred and fifty milliliter Hoagland's solution with appointed concentration of GABA or PEG were changed every 2 days in treatment. The GABA concentration was determined by our preliminary experiment. Each treatment had four independent biological replicates, there were 16 pots plants in total. leaf samples were collected at the $0,10,17$ days of PEG treatment.

\section{Chemicals Treatment in Vitro Condition}

To further explore whether a higher GABA concentration plays a positive role in white clover responsing to drought stress, the plant leaves were directly collected and treated in vitro for 16h as follows: (1) Control; (2) 4N (GAD activity inhibitor); (3) AG (CuAO and PAO activity inhibitor); (4) 4N+PEG; (5) AG+PEG; (6) PEG; (7) GABA+PEG. Six independent replicates were applied for each treatment.

\section{Physiological Parameters \\ Relative Water Content, Electrolytic Leakage, and Malondialdehyde}

$0.1 \mathrm{~g}$ fresh leaves (FW) from each treatment were wrapped in gauze and completely immersed in distilled water, and then put into refrigerator at $4^{\circ} \mathrm{C}$ for $24 \mathrm{~h}$. Saturated weight (SW) were weighed after the leaves were removed from distilled water and gently dried. Subsequently, leaf samples were put into kraft paper bags in oven, then inactivated at $105^{\circ} \mathrm{C}$ for $30 \mathrm{~min}$ and dried at $75^{\circ} \mathrm{C}$ for $48 \mathrm{~h}$ to determine dry weight (DW). Leaf relative water content(RWC)was determined by using the following formula (Barrs and Weatherley, 1962):

$$
\mathrm{RWC}(\%)=\frac{F W-D W}{S W-D W} \times 100 \%
$$

For the measurement of electrolyte leakage (EL), $0.1 \mathrm{~g}$ fresh leaves were put into the tube with deionized water $(15 \mathrm{~mL})$. Leaf samples were incubated for $24 \mathrm{~h}$ at room temperature and initial conductivity of the solution $\left(\mathrm{C}_{\text {initial }}\right)$ were determined by using a conductivity meter (YSI Model 32, Yellow Spring, OH). After that, leaf samples were boiled at $100^{\circ} \mathrm{C}$ for $30 \mathrm{~min}$ and cooled to room temperature to measure the final conductivity $\left(\mathrm{C}_{\text {final }}\right)$. EL was calculated by using the following formula (Blum and Ebercon, 1981):

$$
\mathrm{EL}(\%)=\frac{C_{\text {initial }}}{C_{\text {final }}} \times 100 \%
$$

Malondialdehyde (MDA) was measured obeying method of Dhindsa et al. (1981). Leaves $(0.1 \mathrm{~g})$ was ground on ice bath with $1.5 \mathrm{~mL} 150 \mathrm{mmol} / \mathrm{L}$ phosphate buffer saline (PBS, $\mathrm{pH}=$ 7.8). The homogenate was centrifuged at $15,000 \mathrm{~g}$ for $40 \mathrm{~min}$ at $4{ }^{\circ}$ C. $0.5 \mathrm{~mL}$ MDA crude enzyme solution (the supernatant after centrifugation) and $1.0 \mathrm{~mL}$ mixture [including $20 \% \mathrm{w} / \mathrm{v}$ trichloroacetic acid (TCA) and $0.5 \% \mathrm{w} / \mathrm{v}$ thiobarbituric acid] were incubated at $95^{\circ} \mathrm{C}$ for $15 \mathrm{~min}$, and then rapid cooled to room temperature on ice bath (shaken to prevent the formation of bubbles). The mixture was centrifuged at $10,000 \mathrm{~g}$ for $10 \mathrm{~min}$. The absorbance of the supernatant was determined at 532 and $600 \mathrm{~nm}$. MDA content was expressed as nmol/g DW.

\section{Glutamic, GABA Content and Metabolism Enzyme Activity}

Glu content and Alpha ketone glutarate dehydrogenase $(\alpha-$ $\mathrm{KGDH}$ ) activity were determined by using Assay Kits (Suzhou Comin Biotechnology Co., Ltd., China) according to the manufacturer's protocol.

The endogenous GABA content was determined by Berthelot reaction with some modifications (Guijin and Bown, 1997). Leaves $(0.1 \mathrm{~g})$ were ground with methanol at room temperature. The homogenate was centrifuged at $5,000 \mathrm{~g}$ for $15 \mathrm{~min}$ and discarded the supernatant (2-3 times). The sediment was redissolved in $1.5 \mathrm{~mL}$ distilled water. Subsequently, the samples were heated in water bath at $50^{\circ} \mathrm{C}$ for $2 \mathrm{~h}$, and then centrifuged at $7,000 \mathrm{~g}$ for $15 \mathrm{~min}$. One milliliter supernatant was added $0.1 \mathrm{~mL} 2 \mathrm{~mol} / \mathrm{L} \mathrm{AlCl}_{3}$ and oscillated. The mixture was cooled to room temperature and then centrifuged at $12,000 \mathrm{~g}$ for $10 \mathrm{~min}$. The supernatant $(0.5 \mathrm{~mL})$ was shaken for $5 \mathrm{~min}$ with $0.3 \mathrm{~mL}$ $\mathrm{KOH}$ and centrifuged at $12,000 \mathrm{~g}$ for $5 \mathrm{~min}$. The resulting supernatant was used to measure the content of GABA based on the following procedure: $0.3 \mathrm{~mL}$ supernatant was added to the reaction solutions [including $0.5 \mathrm{~mL} 0.1 \mathrm{~mol} / \mathrm{L}$ sodium tetraborate $(\mathrm{pH}=10.0), 0.4 \mathrm{~mL} 6 \%$ phenol and $0.6 \mathrm{~mL} 5 \%$ sodium hypochlorite]. The mixture was put into a boiling water for $10 \mathrm{~min}$ and rapidly placed in ice bath for $5 \mathrm{~min}$. Finally, the solution was shaken with $2 \mathrm{~mL} 60 \%$ ethyl alcohol and measured the absorbance in $645 \mathrm{~nm}$.

GAD and GABA-T activities were determined according to Bartyzel et al. (2003) and Ansari et al. (2005) with some modifications, respectively. $0.1 \mathrm{~g}$ leaves were ground to homogenate with $100 \mathrm{mM}$ Tris-HCL ( $\mathrm{pH} 7.5$ ) (including $1 \mathrm{mM}$ EDTA, $1 \mathrm{mM}$ PMSF, and $10 \%$ glycerol). The mixture was centrifuged at $12,000 \mathrm{~g}$ for $20 \mathrm{~min}$ at $4^{\circ} \mathrm{C}$. The supernatant was transferred to a new tube and used for determination of GAD and GABA-T activities. Enzyme activity was presented as mmol $\mathrm{g}^{-1}$ protein $\mathrm{h}^{-1}$.

\section{Polyamines Content and Metabolic Enzyme Activity}

Free, insoluble bound and soluble conjugated PAs (including Put, Spd and Spm) were quantified according to Duan et al. (2008) with some modifications. Leaves $(0.1 \mathrm{~g})$ were homogenized with $1 \mathrm{~mL}$ perchloriv acid (precool, $5 \%, \mathrm{v} / \mathrm{v}$ ) and incubated at $4^{\circ} \mathrm{C}$ for $1 \mathrm{~h}$. And then the mixture was centrifuged at $12,000 \mathrm{~g}$ for $30 \mathrm{~min}$ at $4{ }^{\circ} \mathrm{C}$. The supernatant was benzoylated as the following process: $500 \mu \mathrm{l}$ supernatant was blended with $2 \mathrm{~mL} \mathrm{NaOH}(2 \mathrm{M})$ and $10 \mu \mathrm{l}$ benzoyl chlorides and incubated $37^{\circ} \mathrm{C}$ for $30 \mathrm{~min}$. Two milliliter saturarted $\mathrm{NaCl}$ solution was used to terminate the reaction. In order to extract benzoyl PAs, $2 \mathrm{~mL}$ cold diethylether was added into the solution and $1 \mathrm{~mL}$ ether phase was evaporated to dryness. The dried product were re-dissolved in $1 \mathrm{~mL}$ methanol to determine the content of PAs.

Polyamines biosynthetic enzyme (including ADC, ODC and SAMDC) activities were assayed according to $\mathrm{Hu}$ et al. (2012). $0.1 \mathrm{~g}$ leaves was ground with $5 \mathrm{~mL}$ extract solution (including 
$50 \mathrm{mmol} / \mathrm{L} \mathrm{PBS}, \mathrm{pH}=6.3$, including $5 \mathrm{mmol} / \mathrm{L}$ EDTA, 0.1 $\mu \mathrm{moI} / \mathrm{L}$ PMSF, $40 \mu \mathrm{mol} / \mathrm{L}$ pyridoxal phosphate, $40 \mu \mathrm{moI} / \mathrm{L}$ insolubility ployvinylpynolidone, $5 \mathrm{mmol} / \mathrm{L}$ dithiothreitol and $24 \mathrm{mmol} / \mathrm{L} \mathrm{Vc}$ ) on ice bath. After centrifugation at $12,000 \mathrm{~g}$ for $40 \mathrm{~min}$ at $4^{\circ} \mathrm{C}$, the supernatant was dialyzed against $3 \mathrm{~mL}$ of $100 \mathrm{mmol} / \mathrm{L}$ PBS ( $\mathrm{pH}$ 8.0) (including $0.05 \mathrm{mmol} / \mathrm{L}$ PLP, 1 $\mathrm{mmol} / \mathrm{L}$ DTT and $0.1 \mathrm{mmol} / \mathrm{L}$ EDTA) for $24 \mathrm{~h}$ in darkness at $4^{\circ}$ C. $0.3 \mathrm{~mL}$ dialyzed enzyme extract solution were mixed with $1.5 \mathrm{~mL}$ of reaction system included $1 \mathrm{~mL} 100 \mathrm{mmol} / \mathrm{L}$ Tris- $\mathrm{HCl}$ buffer $(\mathrm{pH}=7.5$, containing $5 \mathrm{mmol} / \mathrm{L}$ EDTA, $5 \mathrm{mmol} / \mathrm{L}$ DTT and $40 \mu \mathrm{mol} / \mathrm{L} \mathrm{L}$-Arg for determination of ADC, $40 \mu \mathrm{moI} / \mathrm{L}$ L-Orn for determination of ODC or $40 \mu \mathrm{mol} / \mathrm{L}$ determination of S-adenosylmethionine for SAMDC n). Enzyme activity was presented as $\mu \mathrm{mol} \mathrm{g}^{-1}$ protein $\mathrm{h}^{-1}$.

$\mathrm{PAO}$ and $\mathrm{CuAO}$ (Polyamines catabolism enzyme) activities were determined according to $\mathrm{Su}$ et al. (2005) with some modificatuions. $0.5 \mathrm{~g}$ leaves were homogenized with $1.5 \mathrm{~mL}$ $100 \mathrm{mM}$ potassium-PBS ( $\mathrm{pH}$ 6.5) and centrifuged at $10,000 \mathrm{~g}$ for $20 \mathrm{~min}$ at $4{ }^{\circ} \mathrm{C}$. The reaction mixture contained $0.2 \mathrm{~mL}$ supernatant, $2.5 \mathrm{~mL} 100 \mathrm{mM}$ potassium-PBS $(\mathrm{pH}=6.5)$, $0.2 \mathrm{~mL} \quad 4$-aminoantipyrine/ $\mathrm{N}, \quad \mathrm{N}$-dimethylaniline, $\quad 0.1 \mathrm{~mL}$ horseradish peroxidase and $\mathrm{Spd}+\mathrm{Spm}(20 \mathrm{mmol} / \mathrm{L})$ for $\mathrm{PAO}$ determination or Put $(20 \mathrm{mmol} / \mathrm{L})$ for CuAO. The absorbance values were measured at $550 \mathrm{~nm}$ for calculating enzyme activity.

\section{Proline Content and Its Metabolic Enzyme Activity}

Pro content was measured by the ninhydrin method according to Bates et al. (1973). $0.1 \mathrm{~g}$ leaves were extracted in $5 \mathrm{~mL}$ $3 \%$ sulfosalicylic acid and then heated in boiling water for $20 \mathrm{~min}$. The samples were cooled to room temperature and then $1 \mathrm{~mL}$ extract was mixed with $2 \mathrm{~mL}$ glacial acetic acid and $3 \mathrm{~mL}$ ninhydrin reaction mixture. The reaction solution was heated in boiled water at $100^{\circ} \mathrm{C}$ for $40 \mathrm{~min}$ and then put into ice bath mixing with $2.5 \mathrm{~mL}$ toluene. Chromophorecontaining toluene was used for final determine the absorbance at $520 \mathrm{~nm}$.

$\Delta^{1}$-pyrroline-5-carboxylate synthetase (P5CS) activity was determined according to hydrochloric acid amine colorimetric method (Williams and Frank, 1975). Leaves (0.1 g) were homogenized with $0.5 \mathrm{~mol} / \mathrm{L}$ Tri- $\mathrm{HCl}(\mathrm{pH}=7.5), 10 \mathrm{mmol} / \mathrm{L}$ $\mathrm{MgCl}_{2}, 2 \mathrm{mmol} / \mathrm{L}$ Benzyl phthalein fluorine, and 2\% PVP in ice bath. The homogenate was centrifuged at 20,000 $\mathrm{g}$ for $20 \mathrm{~min}$ at $4^{\circ} \mathrm{C}$. The supernatant were mixed with $3 \mathrm{~mL}$ reaction mixture (including $50 \mathrm{mmol} / \mathrm{L}$ Tri- $\mathrm{HCl}, 20 \mathrm{mmol} / \mathrm{L} \mathrm{MgCl} 2,10 \mathrm{mmol} / \mathrm{L}$ ATP, $100 \mathrm{mmol} / \mathrm{L}$ Hydroxamate- $\mathrm{HCl}$, and $50 \mathrm{mmol} / \mathrm{L} \mathrm{L}-\mathrm{Glu}, \mathrm{pH}$ $=7.0$ ) and immediately incubated in $37^{\circ} \mathrm{C}$ water bath for $15 \mathrm{~min}$. In order to terminate the reaction, $3 \mathrm{~mL}$ reaction termination buffer (including $0.5 \mathrm{mmol} / \mathrm{L} \mathrm{HCl}, 5 \% \mathrm{FeCl}_{3}$ and $12 \% \mathrm{TCA}$ ) were added into the solution. Subsequently the absorbance of the reaction solution was measured at $535 \mathrm{~nm}$.

Ornithine $-\delta$ - amino transferase $(\delta$-OAT) activity was analyzed based on Kim et al. (1994). Leaves $(0.1 \mathrm{~g})$ were ground with $100 \mathrm{mmol} / \mathrm{L}$ PBS $(\mathrm{pH}=7.9$, including $1 \mathrm{mmol} / \mathrm{L}$ EDTA$\mathrm{Na}_{2}, 10 \mathrm{mmol} / \mathrm{L} \beta$-mercaptoethanol and $15 \%$ glycerinum) and centrifuged at $15,000 \mathrm{~g}$ for $15 \mathrm{~min}$. The supernatant were mixed with $50 \mathrm{mmol} / \mathrm{L}$ Tris (containing $50 \mathrm{mmol} / \mathrm{L}$ L-ornithine,
$5 \mathrm{mmol} / \mathrm{L} \alpha$-ketoglutaric acid and $0.05 \mathrm{mmol} / \mathrm{L}$ pyridoxal phosphate, $\mathrm{pH}=8.0$ ) and put into water bath for $20 \mathrm{~min}$ at $37^{\circ} \mathrm{C}$. Followed, the mixture with perchloric acid and $2 \%$ ninhydrin were heated in boiling water for $5 \mathrm{~min}$ and centrifuged at $13,000 \mathrm{~g}$ for $30 \mathrm{~min}$. The sediment was redissolved in absolute ethylalcohol. The absorbance of the solution was measured at $510 \mathrm{~nm}$.

Proline dehydrogenase (ProDH) activity was analyzed according to Rena and Splittstoesser (1975) with some modifications. Leaves $(0.1 \mathrm{~g})$ were ground with $100 \mathrm{mmol} / \mathrm{L}$ PBS (including $1 \mathrm{mmol} / \mathrm{L}$ cysteine and $0.1 \mathrm{mmol} / \mathrm{L}$ EDTA-Na, $\mathrm{pH}$ 8.0) and centrifuged at $15,000 \mathrm{~g}$ for $30 \mathrm{~min}$. The supernatant were mixed with enzyme reaction solution (containing 100 $\mathrm{mmol} / \mathrm{L} \mathrm{Na}_{2} \mathrm{CO}_{3}-\mathrm{NaHCO}_{3}$ and $20 \mathrm{mmol} / \mathrm{L} \mathrm{L}-\mathrm{Pro}, \mathrm{pH}=10.3$ ) and then incubated at $32^{\circ} \mathrm{C}$ for $5 \mathrm{~min}$. $50 \mu \mathrm{L}$ nicotinamide adenine dinucleotide (NAD) was added into reaction mixture and immediately monitored with a UV detector at $310 \mathrm{~nm}$.

\section{Quantitative Real-time PCR (qRT-PCR) Analysis}

Total RNA of white clover leaves were extracted by using Plant RNA Kit (GBCBIO Technologies Inc., China) according to the specification. An iScriptTM cDNA Synthesis Kit from USA BioRad Laboratories was used for revers-transcripting RNA to first chain of cDNA. The amplification of $\beta$-Actin was used as an internal control to normalize all data. Primer sequences for $\beta$ Actin, ADC, ODC, CUAO, GAD, PAO, and SMADC were showed in Table 1. The conditions of the PCR protocol for all genes were as follows: $30 \mathrm{~s}$ at $95^{\circ} \mathrm{C}$ and 30 repeats of denaturation at $94^{\circ} \mathrm{C}$ for $30 \mathrm{~s}$, annealing at $58^{\circ} \mathrm{C}(\beta$-Actin, $A D C, O D C$ and $C u A O)$ or $63^{\circ} \mathrm{C}$ (GAD, PAO and $S M A D C$ ) for $30 \mathrm{~s}, 1 \mathrm{~min}$ at $72^{\circ} \mathrm{C}$, followed $72^{\circ} \mathrm{C}$ for $5 \mathrm{~min}$.

\section{Statistical Analysis}

The data was analyzed by using SPSS 19.0 (IBM, Armonk, New York, USA). The statistical significance among treatments were determined using Fischer's least significance difference (LSD) at the 0.05 probability level.

TABLE 1 | All primers used in this experiment.

\begin{tabular}{|c|c|c|c|}
\hline Gene & Gene no. & Primer sequence $\left(5^{\prime}-3^{\prime}\right)$ & $\operatorname{Tm}\left({ }^{\circ} \mathrm{C}\right)$ \\
\hline \multirow[t]{2}{*}{$G A D$} & KX856932 & GCAGCTAGTGGCGGCTTCAT & 63 \\
\hline & & CGATTCCAGCATAGACAAGACCATA & \\
\hline \multirow[t]{2}{*}{$A D C$} & KX856933 & ATCTGCTGCTACCCTTCGTGG & 58 \\
\hline & & GCTGTTCAATCCCTAAAGTGCC & \\
\hline \multirow[t]{2}{*}{ ODC } & KX856934 & AACTTCCAACAGTCAAGCCTाTCT & 63 \\
\hline & & GGTTGGCATAGATGATTCGGTC & \\
\hline \multirow[t]{2}{*}{ SAMDC } & KX856936 & GCAGCCAAGATGACCAACAAC & 63 \\
\hline & & GAAACAGCAGCACCTTCAACAG & \\
\hline \multirow[t]{2}{*}{ CUAO } & KX856931 & CGAACAAAGCGTTGCGATAGA & 58 \\
\hline & & GTACTCTTCTCTTCTCCAAACCACC & \\
\hline \multirow[t]{2}{*}{ PAO } & KX856935 & GAGGTTGCGGGTTCCTGTAGAT & 63 \\
\hline & & GGCAGCCATTGTTCCAGTAGAGTAT & \\
\hline \multirow[t]{2}{*}{$\beta$-Actin } & JF968419 & TTACAATGAATTGCGTGTTG & 58 \\
\hline & & AGAGGACAGCCTGAATGG & \\
\hline
\end{tabular}




\section{RESULTS}

\section{Phenotype, RWC, EL, and MDA Content of White Clover Plants}

No significant differences were observed in appearance performance, RWC, EL, and MDA content among all treatments under control conditions in white clover (Figure 1). Exogenous application of GABA effectively mitigated drought-induced leaf wilting (Figure 1A). PEG treatment gradually decreased leaf RWC, however, GABA-pretreated plants showed significantly higher RWC compared with PEG treatment alone during PEG-induced drought stress (Figure 1B). Meanwhile, EL and MDA content continually raised with the duration of drought, but GABA application observably inhibited the rising trend (Figures 1C,D).

\section{Endogenous GABA Content and GABA-Shunt Metabolism}

Exogenous application of GABA greatly enhanced endogenous GABA content in white clover under non-stress condition
(Figure 2A). PEG-induced drought stress caused a rapid accumulation of endogenous GABA contents, however, GABA+PEG treatment showed significantly 33.33 and $23.08 \%$ higher GABA contents compared with PEG treatment at 10 and 17 days of drought, respectively. The activities of GABA-T and $\alpha-\mathrm{KGDH}$ between different treatments had no significant differences under well-watered conditions. Drought induced a gradual increase in GABA-T and $\alpha-\mathrm{KGDH}$ activities, but higher GABA-T and $\alpha-\mathrm{KGDH}$ activities were observed in GABA pretreatments than in non-GABA pretreatments under drought stress, except an opposite GABA-T activity at 10 days of drought (Figures 2B,C). Compared with PEG treated plants, $\alpha-\mathrm{KGDH}$ activities of GABA+PEG treated plants increased by $50.71 \%$ at 17 days of drought stress.

Glu content, GAD activity and GAD gene expression all gradually increased with prolonged drought stress, and GABA pretreated plants maintained significantly higher Glu content than non-pretreated plants along with a visibly suppression in GAD activity under both control and stressful conditions (Figures 2D-F). GAD activity in GABA+PEG treated plants was
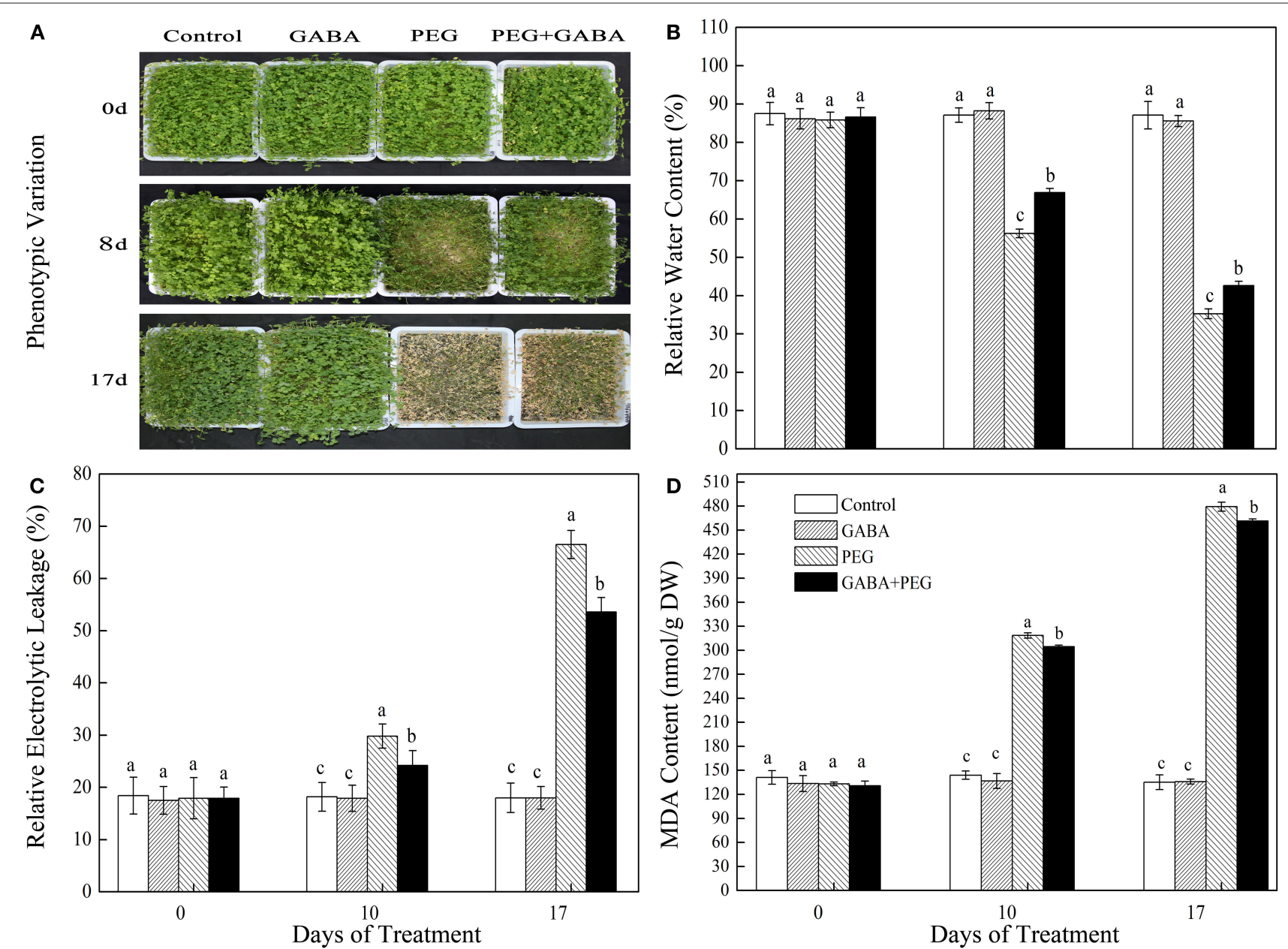

FIGURE 1 | Appearance performance (A), RWC (B), EL (C), and MDA content (D) of white clover in different treatments. Vertical columns indicate Mean \pm std ( $n=$ 4). The same letter indicates no significant difference and the different letter indicate significant difference under a particular day of treatment. $(P<0.05)$. 

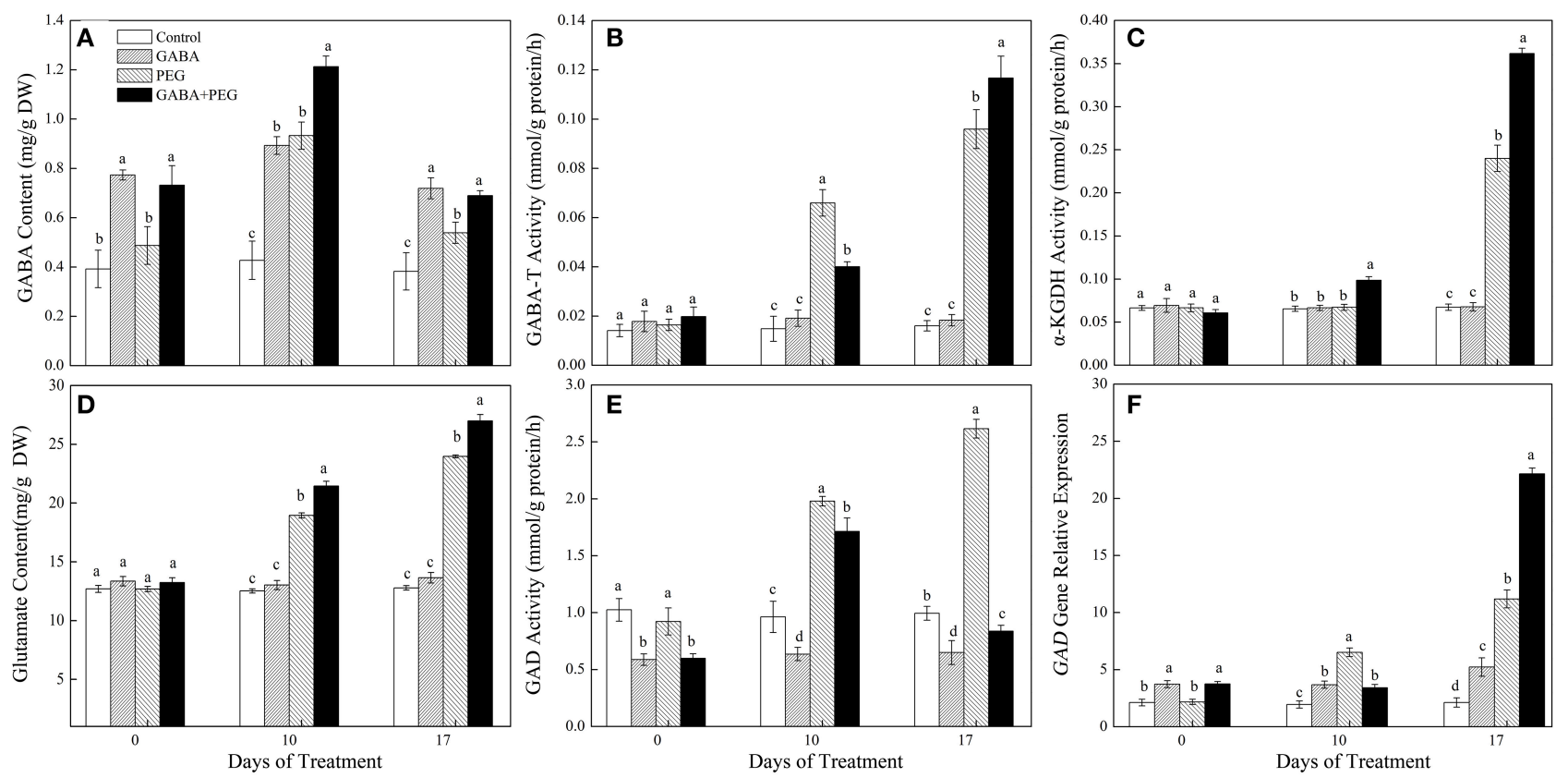

FIGURE 2 | GABA content (A), GABA-T activity (B), $\alpha-K G D H$ activity (C), Glu content (D), GAD activity (E), and GAD gene relative expression (F) of white clover in different treatments. Vertical columns indicate Mean $\pm \operatorname{std}(n=4)$. The same letter indicates no significant difference and the different letter indicate significant difference under a particular day of treatment. $(P<0.05)$.

210.71\% lower than that in PEG-treated plants at 17 days of drought (Figure 2E). GAD gene expression was significantly upregulated by exogenous GABA under well-watered conditions. A significantly higher of $G A D$ gene relative expression levels in GABA+PEG treated plants were detected at 17 days while lower at 10 days when compared to only PEG-treated plants (Figure 2F).

\section{Endogenous Polyamines Contents}

Under well-watered conditions, treatments with GABA had higher free, insoluble bound and total Put contents than treatments without GABA, accompanied by no significant changes for soluble conjugated Put content in 4 different treatments. Increased free, insoluble bound, soluble conjugated and total Put contents were detected under drought stress. Furthermore, GABA+PEG treated plants showed remarkably higher free and total, but lower bound and conjugated Put contents than PEG treated plants alone (Figures 3A,D,G,J). GABA+PEG treated plants showed 41.65 and $92.69 \%$ higher free Put content than PEG treated plants at 10 and 17 days of drought stress, respectively.

Treatments with GABA had lower free and total Spd contents than treatments without GABA under well-watered conditions, meanwhile bound and conjugated Spd contents did not significantly changed. Free, bound, conjugated and total Spd contents obviously increased under PEG-induced drought stress and exogenous application of GABA further enhanced different forms and total Spd contents (Figures 3B,E,H,K). GABA+PEG treated plants showed 30.34 and $10.03 \%$ higher free and bound
Spd at 10 days, $15.62 \%$ higher conjugated Spd at 17 days than PEG-treated plants, respectively.

Exogenous application of GABA significantly decreased free and total Spm contents, and had no significant alteration to bound and conjugated Spm content under well-watered conditions. PEG-induced drought stress greatly promoted free, bound, conjugated and total Spm accumulation in leaves. However, GABA pretreated plants showed significantly lower free Spm content, higher bound and conjugated Spm contents compared with non-treated GABA plants at 10 and 17 days of drought stress. As a result, there was no significant differences in total Spm content between GABA+PEG treated and PEG-treated plants (Figures 3C,F,I,L).

\section{Polyamines Biosynthesis}

Under well-watered condition, ADC and SAMDC activities had no significant differences in four treatments, and GABA treatment significantly increased ODC activities (Figures 4A-C). $\mathrm{ADC}$ and SAMDC activities were increasingly induced by PEG-induced drought stress, and GABA pretreatment further enhanced this two enzymatic activities during drought stress, but ODC activity only at 10 days of drought (Figures $4 \mathrm{~A}-\mathrm{C}$ ). GABA induced a significant decrease in both $A D C$ and $S A M D C$ gene expression, and had no effect on $O D C$ expression under well-watered conditions. Drought stress generated an increase and a decrease in both of $A D C$ and $S A M D C$ gene expression at 10 and 17 days respectively, and a continuous upregulation in $O D C$ expression (Figures $4 D-F$ ). GABA treated 


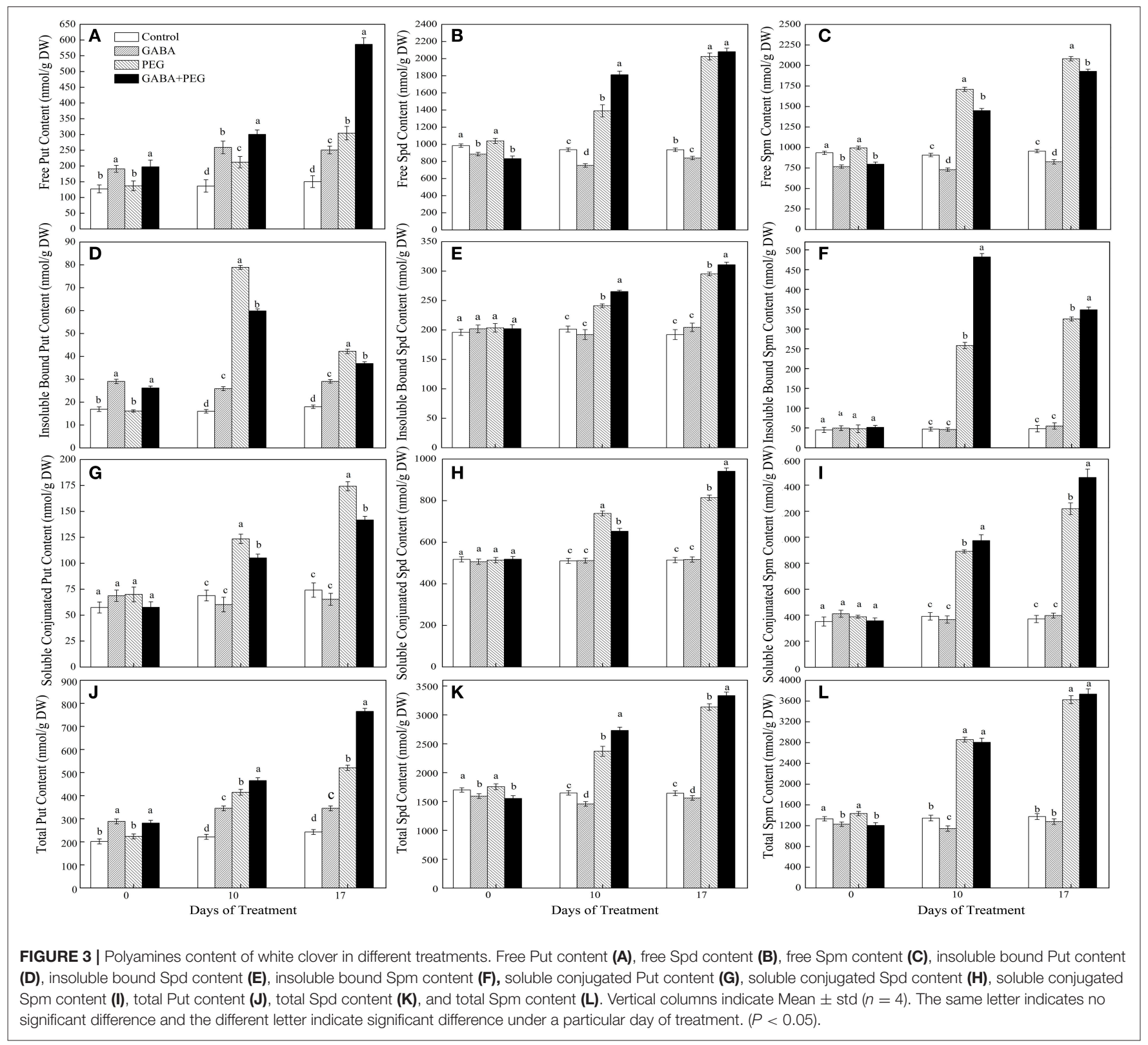

plants showed a significantly lower and higher expression in three genes at 10 and 17 days of drought stress, respectively (Figures 4D-F).

\section{Polyamines Catabolism}

Exogenous application of GABA significantly inhibited PAO and $\mathrm{CuAO}$ activity under both well-watered and stressful conditions. PEG-induced drought stress up-regulated PAO and $\mathrm{CuAO}$ activities and genes expression. Compared with PEG treatment, GABA pretreatment decreased PAO activity by 30.82 and $12.06 \%, \mathrm{CuAO}$ activity by 39.10 and $27.13 \%$ at 10 and 17 days of drought, respectively (Figures 5A,B). GABA had no effect on $P A O$ and $C U A O$ genes expression under normal conditions, but GABA pretreated plants showed a greatly lower and higher expression level of this two genes than nontreated plants at 10 and 17 days of drought stress, respectively (Figures 5C,D).

\section{Proline Metabolism}

Proline contents had no observable difference in all treatments along with significantly reduced $\delta$-OAT and ProDH activity but increased P5CS activity in GABA treatments before PEG-induced drought stress (Figure 6). Drought quickly induced proline accumulation corresponding to boosting 8 -OAT and P5CS activity involved in proline synthesis, but restraining ProDH activity responsible for proline degradation (Figures 6A-D). GABA still showed a remarkably restraining effect on the $\delta$-OAT activity, but a stimulative effect on both P5CS and ProDH activity 

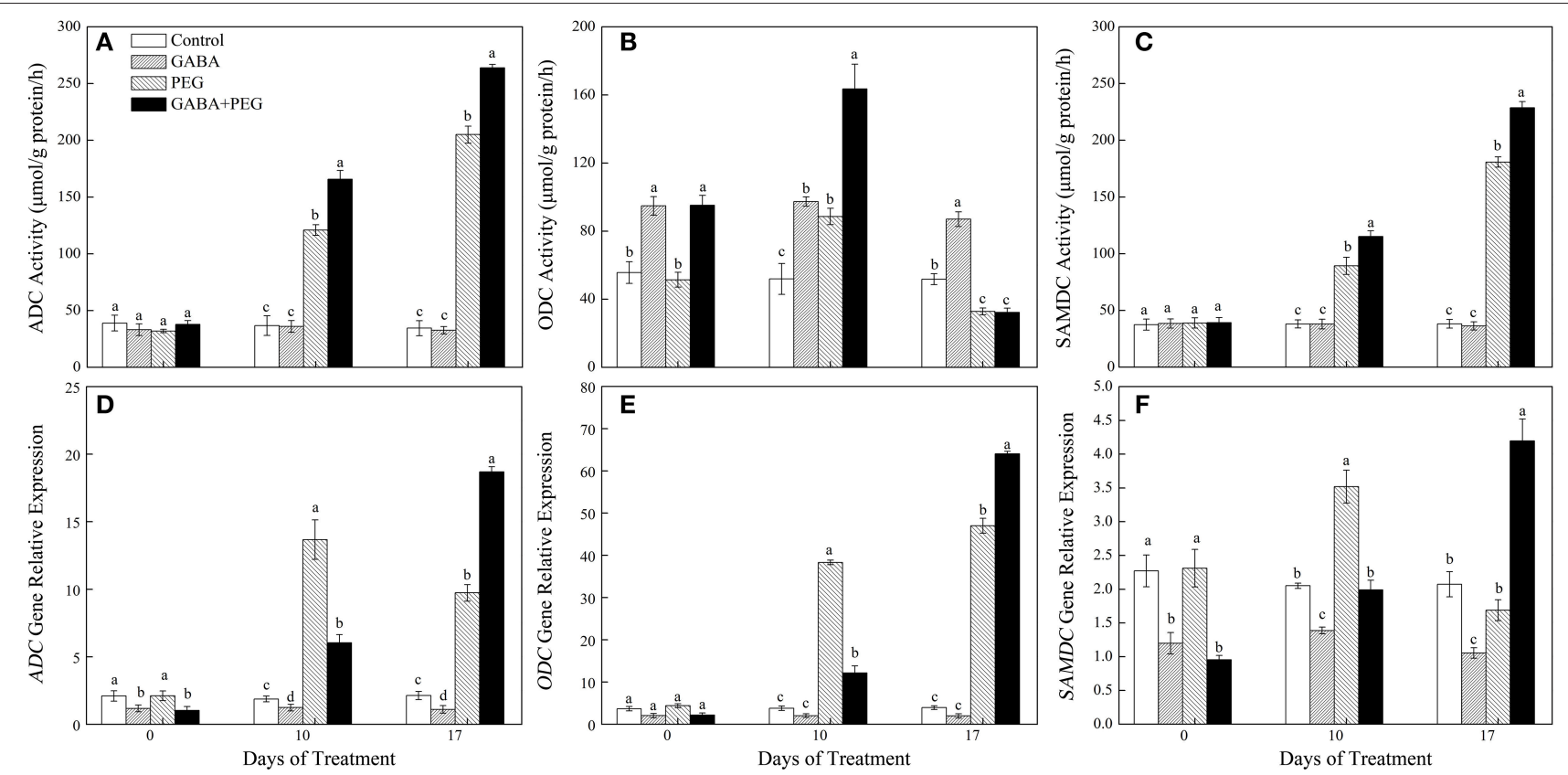

FIGURE 4 | Activities of key enzymes that catalyze polyamine synthesis. ADC (A), ODC (B), SAMDC (C) and relative expression of genes ADC (D), ODC (E), and SAMDC (F) in white clover leaves under different treatments. Vertical columns indicate Mean \pm std $(n=4)$. The same letter indicates no significant difference and the different letter indicate significant difference under a particular day of treatment. $(P<0.05)$.

under PEG-induced drought stress, resulting in a 55.76\% higher proline content in GABA-pretreated plants compared to nonpretreated plants at 10 days of drought stress (Figures 6A-D)

\section{Effects of Exogenous Inhibitor of GABA Biosynthesis on Physiological Variation under Drought Stress}

To further verify the effect of increased endogenous GABA concentration on eliminating drought stress, a pharmacological assay was designed. As shown in Figure 7, both 4N (GAD activity inhibitor) and $\mathrm{AG}$ ( $\mathrm{CuAO}$ and PAO activity inhibitor) could significantly reduce endogenous GABA content of treatments under water and PEG conditions, but the treatment combined GABA with PEG showed significant higher endogenous GABA content than other treatments (Figure 7D). RWC, EL, and MDA content of treatments without PEG had no significant differences. Treatment combined PEG with $4 \mathrm{~N}$ or AG exhibited significantly lower RWC, higher EL and MDA content than only PEG treatment. Meanwhile, treatment combined PEG with GABA showed the opposite pattern compared with only PEG treatment (Figures 7A-C).

\section{DISCUSSION}

In plants, GABA was firstly discovered in potato (Solanum tuberosum) tubers in 1949 (Steward et al., 1949). Subsequently, more and more literatures reported that endogenous GABA obviously accumulated when plant suffering from various stresses (Alan and Frank, 2000). Meanwhile, transporters and receptors of GABA were found successively. It was reported that drought could increase the activities of ProTs and AAP3 (GABA transporters) which regulate GABA entering into plant cells across cell membrane (Rentsch, 1998; Ramesh et al., 2017). In addition, GABA could regulate the release of $\mathrm{Ca}^{2+}$ from the intracellular $\mathrm{Ca}^{2+}$ store by bounding to its receptors (GLRs and ALMTs) and then modulate the activity of GAD (Cholewa et al., 1997; Malhó, 1999; Lancien and Roberts, 2006). Although these findings, the metabolic effects of GABA on drought tolerance is still not fully understood in plants. Therefore, this study was designed to explain how the GABA concentration affects the metabolic pathway associated with GABA synthesis and catabolism in white clover response to drought stress

\section{GABA Accumulation Could Effectively Relieve Drought Damage of Plants}

Increased EL and MDA accumulation were considered as the indicators of membrane damage and lipid peroxidation induced by excessive ROS generation during stress. White clovers gradually showed the symptom of wilting accompanied by the decrease of RWC as well as the increases of EL and MDA content during PEG-induced water stress. However, pretreatment with GABA effectively alleviate drought-induced leaf wilting and improve membrane stability (decreases in EL and MDA content) under drought stress. The positive effects of exogenous supply of GABA on mitigating drought damage through the maintenance of membrane stability were also found in perennial ryegrass (Lolium perenne) and black pepper (Krishnan et al., 2013; Vijayakumari and Puthur, 2015). These results 

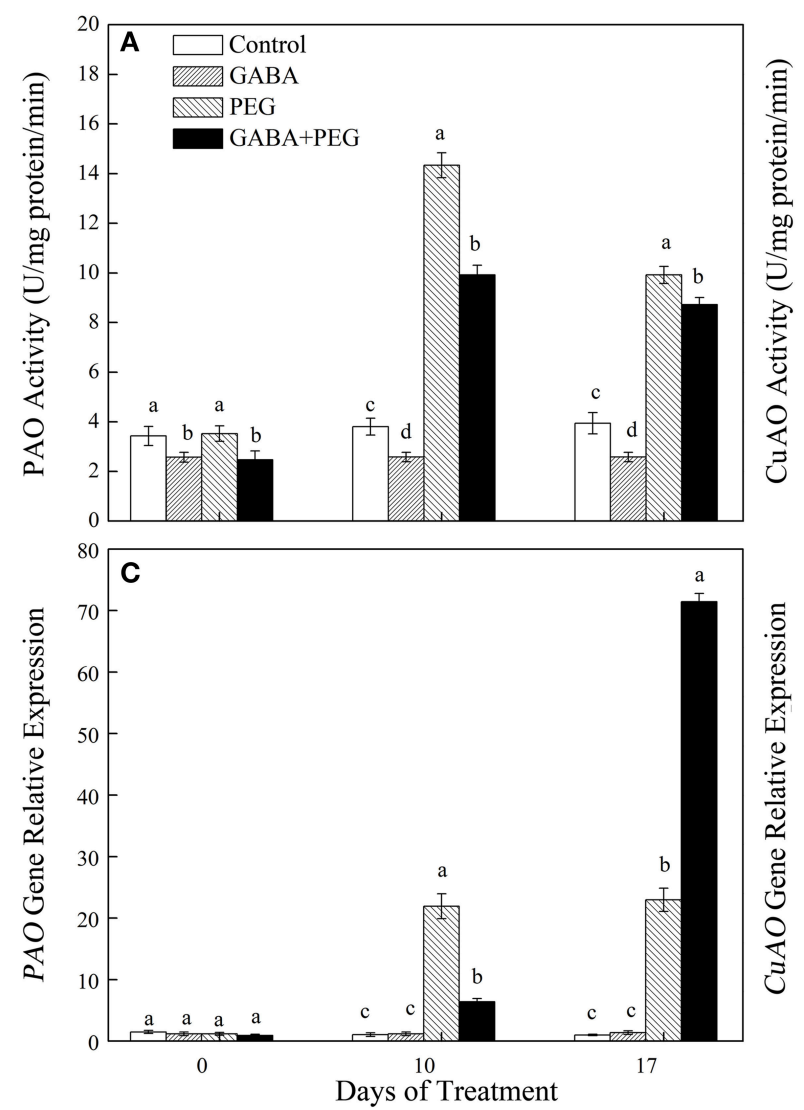
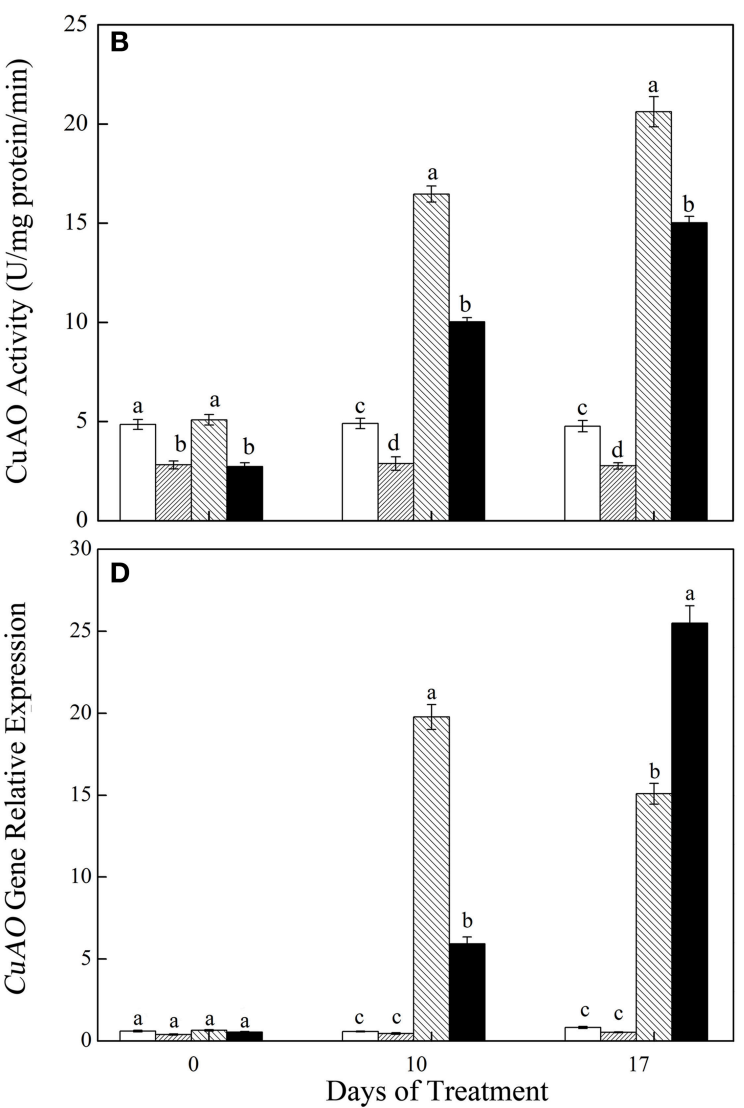

FIGURE 5 | Activities of key enzymes that catalyze polyamine catabolism, PAO (A) and CuAO (B) and relative expression of genes, PAO (C) and CuAO (D) of white clover at different treatments. Vertical columns indicate Mean \pm std $(n=4)$. The same letter indicates no significant difference and the different letter indicate significant difference under a particular day of treatment. $(P<0.05)$.

suggested that GABA played an important role in protecting plants from oxidative stress. The pharmacological assay further confirmed the beneficial effects of elevated endogenous GABA level on the alleviation of drought-induced damage in white clover.

\section{GABA Shunt and Stress Tolerance in Plants}

Three enzymes involved in GABA shunt are detected in this study. GAD is a cytosolic acidification-activated enzyme which catalyzes irreversible decarboxylation of glutamate to generate GABA. The other two steps of GABA shunt proceed in mitochondria associated with TCA cycle. GABA is reversibly converted into SSA by GABA-T and then SSA is oxidized to produce succinate by SSADH linking with TCA cycle. The potential functions of GABA shunt involved in the balance of $\mathrm{C} / \mathrm{N}$ metabolism and the maintenance of integrality of TCA cycle have been well documented (Fait et al., 2008). In our experiment, application of exogenous GABA significantly increased the endogenous GABA concentration, which was similar to the findings of $\mathrm{Hu}$ et al. (2015) and Wang et al. (2014). Our pharmacological assay also proved that both Glu and PAs pathway contributed to the increase of endogenous
GABA concentration. In addition, a higher endogenous GABA concentration and a lower GAD activity were also found under both control and drought conditions, implicating a feedback inhibition between GABA and drought-induced GAD activity. A similar result has been found in hypoxin-stressed melon roots (Wang et al., 2014). A direct suppression of GAD activity induced by exogenous GABA might make a greater contribution to the increase in Glu content due to the decrease in Glu consumption for GABA synthesis.

Interestingly, the pathway of GABA catabolism was further accelerated by exogenous GABA application due to higher activities of GABA-T and a-KGDH. Particularly, GABA-T catalyzes GABA to glutamate or alanine at the first step of GABA degradation. In addition, a-ketoglutarate dehydrogenase (a-KGDH) which catalyzes a-ketoglutarate into succinate in TCA cycle was regarded as a major enzyme for linking GABA shunt and TCA cycle (Bouché and Fromm, 2004). Therefore, the improvement of GABA-T and a-KGDH activities indicated higher GABA catabolism and subsequent TCA metabolic process, resulting in a rapid accumulation of Glu. Besides, lower GAD activity and greater GABA catabolism accounted for the increased Glu content in GABA treatments, which was also found 

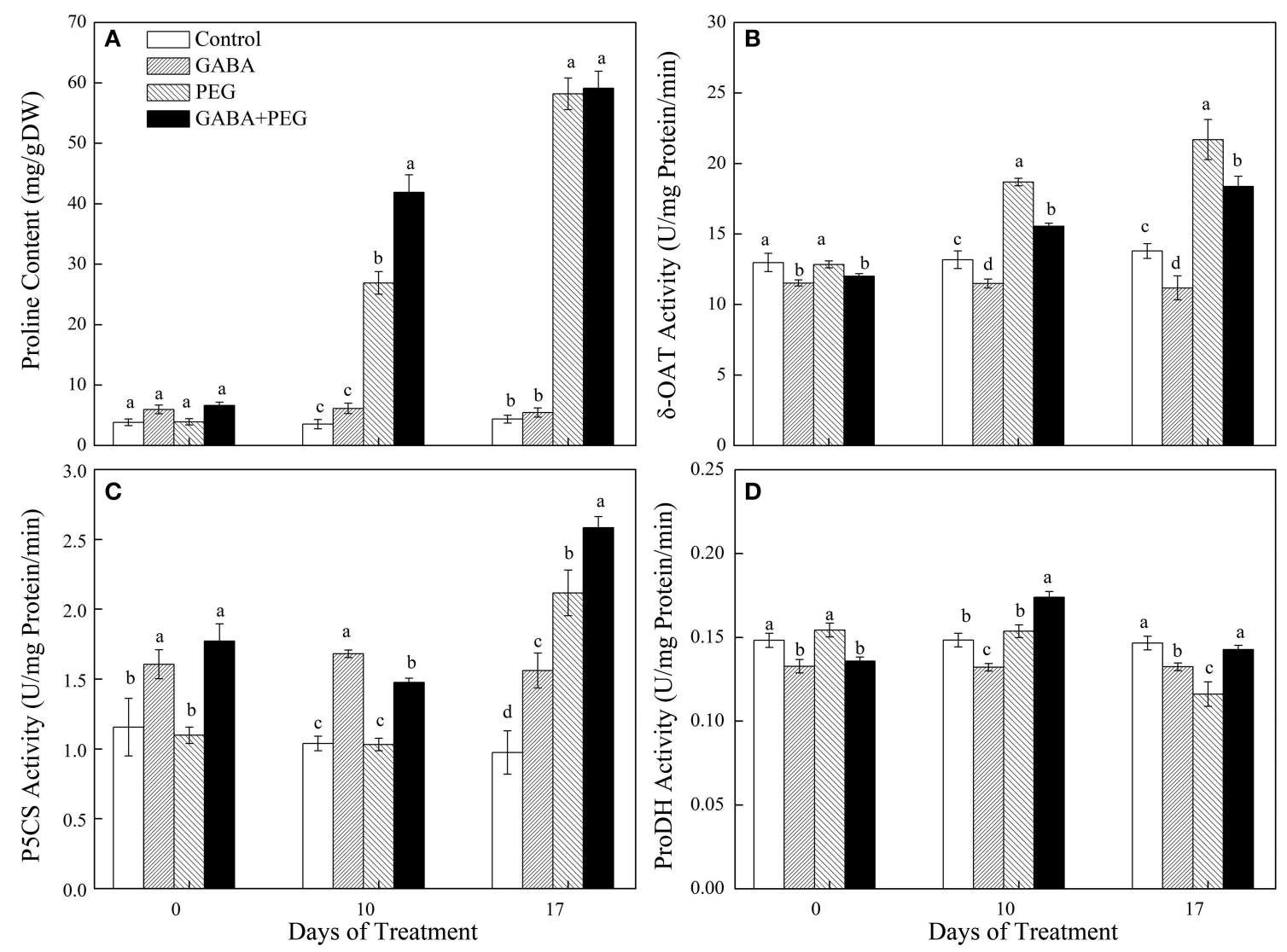

FIGURE 6 | Changes in proline content (A) and key enzymes activity of $\delta$-OAT (B), P5CS (C), and ProDH (D) of white clover at different treatments. Vertical columns indicate Mean \pm std $(n=4)$. The same letter indicates no significant difference and the different letter indicate significant difference under a particular day of treatment. $(P<0.05)$

in Brasska napus and rice when suffered from drought stress (Good and Zaplachinski, 1994; Do et al., 2013).

The physiological function of GABA-T and a-KGDH has been well described under normal condition, but was scarcely revealed in stress. Hu et al. (2015) found that GABA-T activity in muskmelon was increased by exogenous GABA application under $\mathrm{Ca}\left(\mathrm{NO}_{3}\right)_{2}$ stress. It was reported that GABA-T was more functional importance in preventing ROS species accumulation, linking $\mathrm{N}$ and $\mathrm{C}$ metabolism under stressful conditions (Renault et al., 2010; Al-Quraan and Al-Share, 2015). In our current study, it is observed that endogenous GABA concentration in plants presented an obvious decrease after reaching the peak in the middle stage of drought. This expenditure on GABA was just coordinated with dramatically increased GABA-T and a-KGDH activities in the last stage of drought, suggesting that GABA might flow into the TCA cycle (Fait et al., 2005; Renault et al., 2010). Taking these results into account, it could be speculated that a decreased GABA synthesis and an increased GABA catabolism induced by exogenous GABA application could play a positive role in the alleviation of drought stress damage to white clover through supplying enough Glu and keeping the fluency of GABA shunt and TCA metabolism under drought stress.

\section{Alteration of Endogenous GABA Concentration Affects Polyamines Metabolism under Drought Stress}

PAs ubiquitously distribute in all eukaryotic cells and mainly include Put, Spd, and Spm which consist of free, conjugated and bounded status in higher plants (Hu et al., 2012). PAs synthesis originates from three pathways and involves three major enzymes: ADC, ODC, and SMADC. ODC or ADC catalyzes the decarboxylation of ornithine or arginine, which is committed step of Put synthesis. The conversion of S-adenosylmethionine into decarboxylated S-adenosylmethionine could be catalyzed by SAMDC, which donates aminopropyl groups to Put to produce Spd or Spm via Spd synthase or Spm synthase, respectively. In addition, PAs catabolism is catalyzed by $\mathrm{CuAO}$ and $\mathrm{PAO}$ (Mattoo et al., 2010; Rangan et al., 2014). PAs accumulation has been observed in different plants under environmental stresses and the key roles of PAs have been well confirmed in plants (Sequera-Mutiozabal et al., 2016). A direct link of GABA and PAs is that PAs catabolism produces GABA via $\mathrm{CuAO}$ or PAO catalysis. The investigation of Yang et al. (2013) revealed that PAs degradation offered approximately 30\% of GABA content in fava beans (vicia fara) under hypoxic stress. In our current 

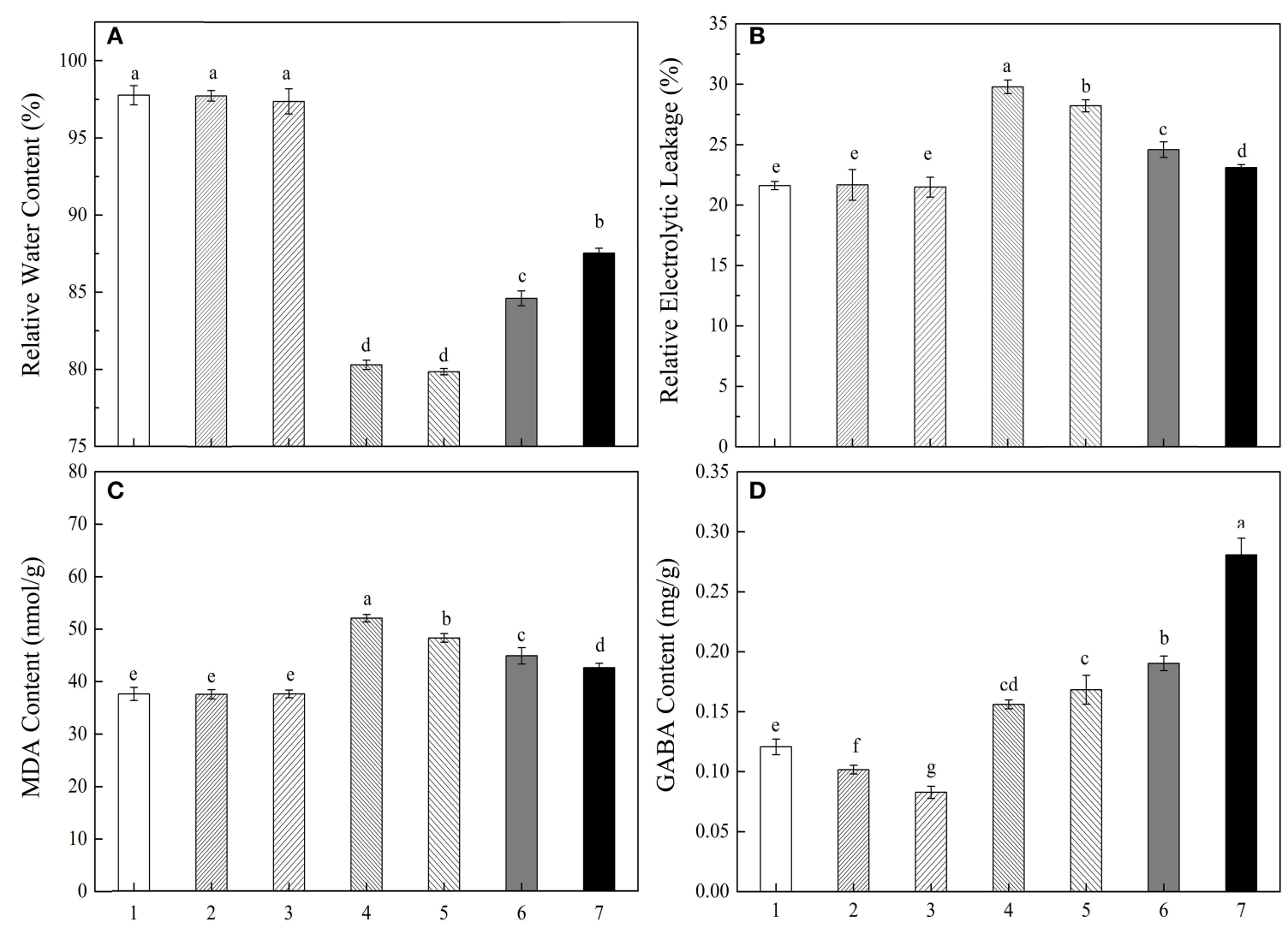

FIGURE 7 | Different treatments on RWC (A), EL (B), MDA (C) and endogenous GABA content (D) of white clover leaves. The plants were treated with: $\mathrm{H}_{2} \mathrm{O}(1) ; 6$ mmol/L 4N (2); 1 mmol/L AG (3); 6 mmol/L 4N + 15\% PEG (4); 1 mmol/L AG + 15\% PEG (5); 15\% PEG (6); 0.05 mmol/L GABA + 15\% PEG (7). Vertical columns indicate Mean \pm std $(n=4)$. The same letter indicates no significant difference and the different letter indicate significant difference between different treatments. $(P<0.05)$

study, drought improved three PAs synthesis enzymes (ADC, ODC and SMADC) activities and their gene expression levels as well as two PAs catabolism enzymes ( $\mathrm{CuAO}$ and $\mathrm{PAO})$ and their gene expression, resulting in increases in three types of PAs. The increased PAs biosynthesis and catabolism was also detected in other plants under stressful conditions (Wang et al., 2014; Hu et al., 2015). Furthermore, GABA enhanced PAs synthesis, but had an inhibitory effect on PAs catabolism, resulting in a higher total PAs content in GABA-treated plants under drought condition. This result implied that the increased endogenous GABA had a negative feedback effect on PAs degradation, which was consistent with findings of Wang et al. (2014).

The overexpression of PA biosynthesis enzymes ( $A D C, O D C$, and $S A M D C$ ) and exogenous application of PA all support that higher PAs content provide better drought resistance in different plant species including rice, fava bean and white clover (Capell et al., 2004; Yang et al., 2013; Li et al., 2016b). In our present study, drought stress induced the increase of three forms of PAs (free, conjugated, and bound), which was consistent with the research of Liu et al. (2006) in maize. GABA further increased total contents of Put, Spd, and Spm in addition to free Put, three forms of Spd, conjugated and bound forms of Spm content, but simultaneously decreased the content of conjugated and bound Put as well as free Spm content. These changes suggested that GABA application did not increase the total content of different PA types but induced a conversions of conjugated and bound Put into free Put, and free Spm into conjugated and bound Spm.

Previous studies reported the correlation between Put level and stress tolerance. For examples, transgenic Arabidopsis plants over-producing Put conferred drought tolerance (Alcázar et al., 2010). Liu et al. (2004) reported that drought-sensitive wheat cultivar accumulated higher free Put level and the conversion of free Put to conjugated Put could contribute to the drought tolerance. Most of researches in favor of that the conversion of free Put to free Spd and Spm could be helpful in increasing stress tolerance (Duan et al., 2008; Alcázar et al., 2010). In our study, we detected an obvious conversion of conjugated and bound Put to free Put, but not free Put to free Spd and Spm in GABA-treated plants under drought stress. This implied that a higher free Put could play a positive role in coping with drought stress because of its active physiological function.

With respect to the conversion of free Spm to conjugate and bound form Spm, the similar result was also detected in other plants in response to stressful conditions (Wang et al., 2014). 


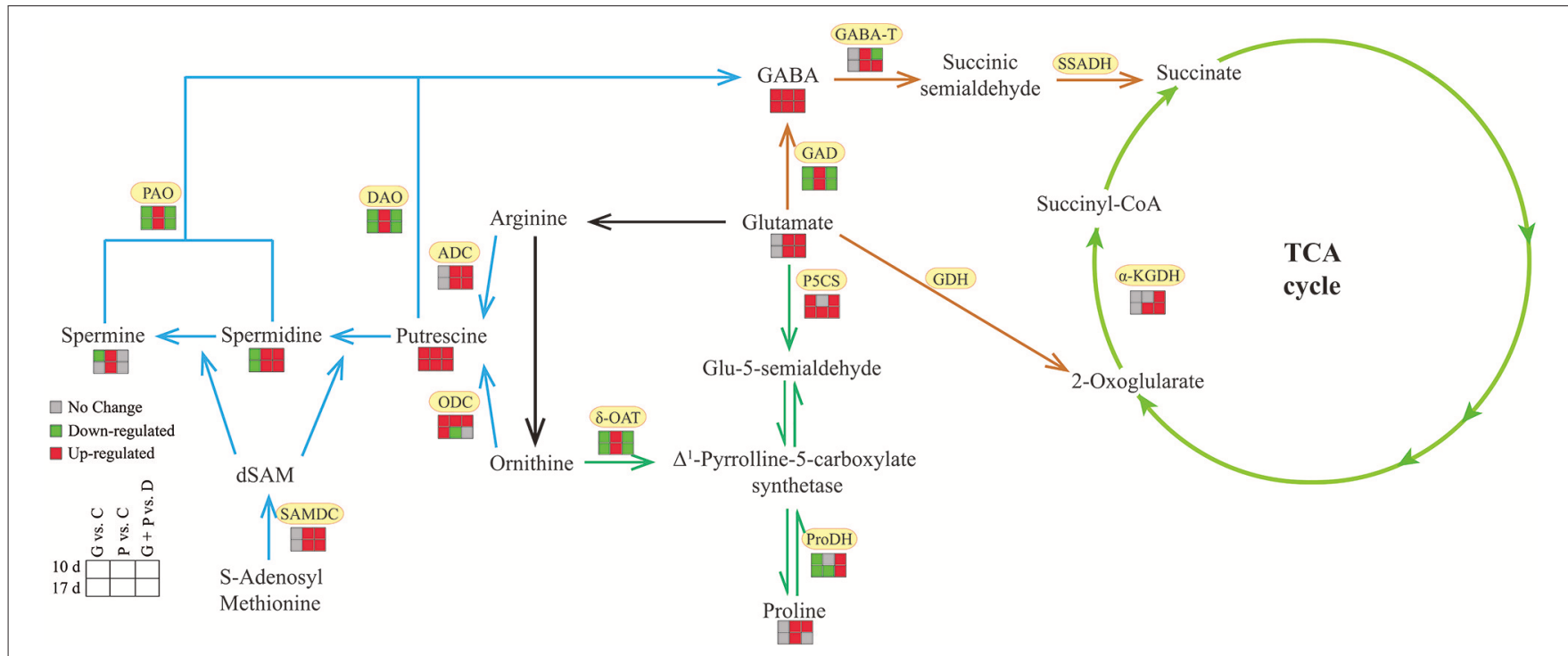

FIGURE 8 | Possible model for exogenous application of GABA improved drought tolerance in white clover associated with GABA-shunt, polyamines and proline metabolism. Blue lines, polyamines metabolism; orange lines, GABA shunt; dark green lines, proline metabolism; light green lines, TCA cycle.

Due to the physiological functions of conjugated and bound PAs involved in stabilizing protein structure and keeping membrane integrity and free forms of PAs as a temporary resource, this conversion could also be physiological important (Roussos and Pontikis, 2007; Trovato et al., 2008). Taking these results together, it could be presumed that both GABA-induced PAs accumulation and conversions of different forms of PAs implicate in drought tolerance in white clover in our current study.

\section{Increased Endogenous GABA Concentration Could Regulate Proline Accumulation in White Clover in Response to Drought Stress}

It has been well known that plant tissues extensively accumulate free Pro during abiotic stress. Recent studies provided the evidence that multiple functions of Pro were closely involved in its metabolism pathway. Pro is synthesized via two pathways from either Glu or ornithine (Orn). Among which, Glu is reversibly catalyzed by $\mathrm{P} 5 \mathrm{CS}$ involved in the synthesis of Pro and $\delta$-OAT catalyzes the conversion of Orn to Pro (Parida et al., 2008). Earlier Vitro assays showed that Pro could scavenge hydroxyl radicals $(\cdot \mathrm{OH})$, which is considered as a most reactive type of ROS species and responsible for serious oxidative damage to cell in stressed plants (Smirnoff and Cumbes, 1989). The work of Hong et al. (2000) further intensified the protective role of Pro in transgenic tobacco (Nicotiana tabacum) under oxidative stress. More recently, Signorelli et al. (2014) presented a non-enzymatic way to form GABA via Pro reaction with $\cdot \mathrm{OH}$ under oxidative stress, suggesting a direct connection between Pro and GABA. In our experiment, exogenous GABA kept Pro content as a low level as control under normal conditions resulting from increased P5CS activities and decreased $\delta$-OAT and ProDH activity which is involved in the degradation of Pro. Under drought stress, GABA further activated drought-induced
P5CS activities and compensated drought-induced the decrease in ProDH activity, but had a depression effect on droughtfacilitated $\delta$-OAT activities, resulting in a higher and similar Pro accumulation in GABA-treated plants compared with nonGABA-treated plants in the middle and last period of drought, respectively. These findings indicated that GABA promoted Pro accumulation and maintained Pro homeostasis under drought stress. However, more and more recent researches approved that a balance between Pro synthesis and catabolism instead of an excessive pro accumulation, played a vital role in plants tolerance against drought stress in addition to traditional functions as compatible solute, ROS scavenger, and energy supply (Sharma et al., 2011; Bhaskara et al., 2015). Therefore, we proposed the positive effects of exogenous GABA on alleviating the oxidative stress associate with Pro accumulation and homeostasis in white clover under drought condition.

\section{CONCLUSION}

In this study, we detected the effect of exogenous GABA application on drought tolerance and metabolic changes of GABA, Pro, PAs synthesis and degradation in white clover under drought conditions (Figure 8). The increased endogenous GABA concentration induced by exogenous application of GABA effectively reduced drought damage in white clovers. A higher endogenous GABA concentration suppressed GABA synthesis, but enhanced GABA catabolism, resulting in an increase of glutamate content. In addition, exogenous application of GABA also improved PAs synthesis, but inhibited PAs catabolism. As a result, the total content of three types of PAs were further increased, along with a conversion of conjugated and bound Put into free Put as well as free Spm into conjugated and bound forms. The increased activities of P5CS and ProDH and the inhibited $\delta$-OAT activities could account for a higher proline 
accumulation in the middle period of drought. Based on these findings, we proposed that enhanced concentrations of Glu, PAs and Pro, the conversion of Put and Spm forms, and Pro homeostasis induced by exogenous GABA could play positive roles in alleviating drought-induced damage in white clover.

\section{AUTHOR CONTRIBUTIONS}

YP, BY, and HX conceived the project and designed the experiments; BY, HX, and Y-PL performed the

\section{REFERENCES}

Alan, M. K., and Frank, J. T. (2000). Gamma Aminobutyric Acid (GABA) and plant responses to stress. Crit. Rev. Plant Sci. 19, 479-509. doi: 10.1016/S0735-2689(01)80006-X

Alcázar, R., Planas, J., Saxena, T., Zarza, X., Bortolotti, C., Cuevas, J., et al. (2010). Putrescine accumulation confers drought tolerance in transgenic Arabidopsis plants over-expressing the homologous Arginine decarboxylase 2 gene. Plant Physiol. Biochem. 48, 547-552. doi: 10.1016/j.plaphy.2010. 02.002

Al-Quraan, N. A., and Al-Share, A. T. (2015). Characterization of the $\gamma$ aminobutyric acid shunt pathway and oxidative damage in Arabidopsis thaliana pop 2 mutants under various abiotic stresses. Biol. Plant. 60, 132-138. doi: 10.1007/s10535-015-0563-5

Al-Quraan, N. A., Sartawe, F. A., and Qaryouti, M. M. (2013). Characterization of gamma-aminobutyric acid metabolism and oxidative damage in wheat (Triticum aestivum L.) seedlings under salt and osmotic stress. J. Plant Physiol. 170, 1003-1009. doi: 10.1016/j.jplph.2013. 02.010

Annicchiarico, P., and Piano, E. (2004). Indirect selection for root development of white clover and implications for drought tolerance. J. Agron. Crop Sci. 190, 28-34. doi: 10.1046/j.0931-2250.2003.00 070.x

Ansari, M. I., Lee, R.-H., and Chen, S.-C. G. (2005). A novel senescence-associated gene encoding gamma-aminobutyric acid (GABA):pyruvate transaminase is upregulated during rice leaf senescence. Physiol. Plant. 123, 1-8. doi: 10.1111/j.1399-3054.2004.00430.x

Barrs, H. D., and Weatherley, P. E. (1962). A re-examination of the relative turgidity technique for estimating water deficits in leaves. Aust. J. Biol. Sci. 15, 413-428. doi: 10.1071/BI9620413

Bartyzel, I., Pelczar, K., and Paszkowski, A. (2003). Functioning of the $\gamma$-aminobutyrate pathway in wheat seedlings affected by osmotic stress. Biol. Plant. 47, 221-225. doi: 10.1023/B:BIOP.0000022255.011 25.99

Bates, L. S., Waldren, R. P., and Teare, I. D. (1973). Rapid determination of free proline for water-stress studies. Plant Soil 39, 205-207. doi: 10.1007/BF00018060

Bhaskara, G. B., Yang, T. H., and Verslues, P. E. (2015). Dynamic proline metabolism: importance and regulation in water limited environments. Front. Plant Sci. 6:484. doi: 10.3389/fpls.2015.00484

Bhatnagar, P., Glasheen, B. M., Bains, S. K., Long, S. L., Minocha, R., Walter, C., et al. (2001). Transgenic manipulation of the metabolism of polyamines in poplar cells. Plant Physiol. 125, 2139-2153. doi: 10.1104/pp.125. 4.2139

Blum, A., and Ebercon, A. (1981). Cell membrane stability as a measure of drought and heat tolerance in wheat1. Crop Sci. 21, 43. doi: 10.2135/cropsci1981.0011183X002100010013x

Bouché, N., and Fromm, H. (2004). GABA in plants: just a metabolite? Trends Plant Sci. 9, 110-115. doi: 10.1016/j.tplants.2004.01.006

Bown, A. W., and Shelp, B. J. (1997). The metabolism and functions of $\gamma$-aminobutyric acid. Plant Physiol. 115, 1-5. doi: 10.1104/pp.11 5.1 .1 experiments; $\mathrm{BY}, \mathrm{HX}, \mathrm{ZL}$, and $\mathrm{YZ}$ analyzed the data; $\mathrm{HX}, \mathrm{ZL}, \mathrm{YZ}$, and GN finalized the manuscript; X-QZ, $\mathrm{XM}, \mathrm{L}-\mathrm{KH}, \mathrm{Y}-\mathrm{HY}$ discussed the results and reviewed the manuscript.

\section{ACKNOWLEDGMENTS}

This research was supported by grant NSFC 31372371 from National Natural Science Foundation of China.

Capell, T., Bassie, L., and Christou, P. (2004). Modulation of the polyamine biosynthetic pathway in transgenic rice confers tolerance to drought stress. Proc. Natl. Acad. Sci. U.S.A. 101, 9909-9914. doi: 10.1073/pnas.0306974101

Cholewa, E., Cholewinski, A. J., Shelp, B. J., Snedden, W. A., and Bown, A. W. (1997). Cold-shock-stimulated $\gamma$-aminobutyric acid synthesis is mediated by an increase in cytosolic $\mathrm{Ca}^{2+}$, not by an increase in cytosolic $\mathrm{H}^{+}$. Can. J. Bot. 4, 265.

Comeau, A., Nodichao, L., Collin, J., Baum, M., Samsatly, J., Hamidou, D., et al. (2010). New approaches for the study of osmotic stress induced by polyethylene glycol (PEG) in cereal species. Cereal Res. Commun. 38, 471-481. doi: 10.1556/CRC.38.2010.4.3

Dhindsa, R. S., Plumb-Dhindsa, P., and Thorpe, T. A. (1981). Leaf senescence: correlated with increased levels of membrane permeability and lipid peroxidation, and decreased levels of superoxide dismutase and catalase. J. Exp. Bot. 32, 93-101. doi: 10.1093/jxb/32.1.93

Do, P. T., Degenkolbe, T., Erban, A., Heyer, A. G., Kopka, J., Köhl, K. I., et al. (2013). Dissecting rice polyamine metabolism under controlled long-term drought stress. PLoS ONE 8:e60325. doi: 10.1371/journal.pone.0060325

Duan, J., Li, J., Guo, S., and Kang, Y. (2008). Exogenous spermidine affects polyamine metabolism in salinity-stressed Cucumis sativus roots and enhances short-term salinity tolerance. J. Plant Physiol. 165, 1620-1635. doi: 10.1016/j.jplph.2007.11.006

Fait, A., Fromm, H., Walter, D., Galili, G., and Fernie, A. R. (2008). Highway or byway: the metabolic role of the GABA shunt in plants. Trends Plant Sci. 13, 14-19. doi: 10.1016/j.tplants.2007.10.005

Fait, A., Yellin, A., and Fromm, H. (2005). GABA shunt deficiencies and accumulation of reactive oxygen intermediates: insight from Arabidopsis mutants. FEBS Lett. 579, 415-420. doi: 10.1016/j.febslet.2004.12.004

Fan, S., and Blake, T. J. (1997). Comparison of polyethylene glycol 3350 induced osmotic stress and soil drying for drought simulation in three woody species. Trees 11, 342-348. doi: 10.1007/s004680050094

Good, A. G., and Zaplachinski, S. T. (1994). The effects of drought stress on free amino acid accumulation and protein synthesis in Brassica napus. Physiol. Plant. 90, 9-14. doi: 10.1111/j.1399-3054.1994.tb02185.x

Guijin, Z., and Bown, A. W. (1997). The rapid determination of $\gamma$-aminobutyric acid. Phytochemistry 44, 1007-1009. doi: 10.1016/S0031-9422(96)00626-7

Hoagland, D. R., and Arnon, D. I. (1950). The water culture method for growing plants without soil. Calif. Agric. Exp. Station Circ. 347, 357-359.

Hong, Z., Lakkineni, K., Zhang, Z., and Verma, D. P. S. (2000). Removal of feedback inhibition of $\delta 1$-pyrroline-5-carboxylate synthetase results in increased proline accumulation and protection of plants from osmotic stress. Plant Physiol. 122, 1129-1136. doi: 10.1104/pp.122.4.1129

Hu, X., Xu, Z., Xu, W., Li, J., Zhao, N., and Zhou, Y. (2015). Application of $\gamma$ aminobutyric acid demonstrates a protective role of polyamine and GABA metabolism in muskmelon seedlings under $\mathrm{Ca}\left(\mathrm{NO}_{3}\right)_{2}$ stress. Plant Physiol. Biochem. 92, 1-10. doi: 10.1016/j.plaphy.2015.04.006

Hu, X., Zhang, Y., Shi, Y., Zhang, Z., Zou, Z., Zhang, H., et al. (2012). Effect of exogenous spermidine on polyamine content and metabolism in tomato exposed to salinity-alkalinity mixed stress. Plant Physiol. Biochem. 57, 200-209. doi: 10.1016/j.plaphy.2012.05.015

Kautz, B., Noga, G., and Hunsche, M. (2015). PEG and drought cause distinct changes in biochemical, physiological and morphological parameters of 
apple seedlings. Acta Physiol. Plant. 37, 1-6. doi: 10.1007/s11738-015-1 914-8

Kim, H. R., Rho, H. W., Park, J. W., Park, B. H., Kim, J. S., and Lee, M. W. (1994). Assay of ornithine aminotransferase with ninhydrin. Anal. Biochem. 223, 205-207. doi: 10.1006/abio.1994.1574

Krishnan, S., Laskowski, K., Shukla, V., and Merewitz, E. B. (2013). Mitigation of drought stress damage by exogenous application of a non-protein amino acid $\gamma$-aminobutyric acid on perennial ryegrass. J. Am. Soc. Hortic. Sci. 138, 358-366. Available online at: http://journal.ashspublications.org/content/138/5/358.full

Lancien, M., and Roberts, M. R. (2006). Regulation of Arabidopsis thaliana 14-33 gene expression by $\gamma$-aminobutyric acid. Plant Cell Environ. 29, 1430-1436. doi: 10.1111/j.1365-3040.2006.01526.x

Li, Y., Fan, Y., Ma, Y., Zhang, Z., Yue, H., Wang, L., et al. (2017). Effects of exogenous $\gamma$-aminobutyric acid (GABA) on photosynthesis and antioxidant system in pepper (Capsicum annuum L.) seedlings under low light stress. J. Plant Growth Regul. 36, 436-449. doi: 10.1007/s00344-016-9 652-8

Li, Z., Yu, J., Peng, Y., and Huang, B. (2016a). Metabolic pathways regulated by $\gamma$-aminobutyric acid (GABA) contributing to heat tolerance in creeping bentgrass (Agrostis stolonifera). Sci. Rep. 6:30338. doi: 10.1038/srep 30338

Li, Z., Zhang, Y., Zhang, X., Peng, Y., Merewitz, E., Ma, X., et al. (2016b). The alterations of endogenous polyamines and phytohormones induced by exogenous application of spermidine regulate antioxidant metabolism, metallothionein and relevant genes conferring drought tolerance in white clover. Environ. Exp. Bot. 124, 22-38. doi: 10.1016/j.envexpbot.2015. 12.004

Liu, H. P., Dong, B. H., Zhang, Y. Y., Liu, Z. P., and Liu, Y. L. (2004). Relationship between osmotic stress and the levels of free, conjugated and bound polyamines in leaves of wheat seedlings. Plant Sci. 166, 1261-1267. doi: 10.1016/j.plantsci.2003.12.039

Liu, H., Ji, X., Liu, T., Shi, L., and Chaohai, L. (2006). Effect of osmotic stress on the contents of different form polyamines in leaves of maize seedlings. Acta 32, 1430-1436.

Malekzadeh, P., Khara, J., and Heydari, R. (2014). Alleviating effects of exogenous $\gamma$-aminobutiric acid on tomato seedling under chilling stress. Physiol. Mol. Biol. Plants 20, 133-137. doi: 10.1007/s12298-013-0203-5

Malhó, R. (1999). Coding information in plant cells: the multiple roles of $\mathrm{Ca}^{2+}$ as a second messenger. Plant Biol. 1, 487-494. doi: 10.1111/j.1438-8677.1999.tb00774.x

Mattoo, A. K., Minocha, S. C., Minocha, R., and Handa, A. K. (2010). Polyamines and cellular metabolism in plants: transgenic approaches reveal different responses to diamine putrescine versus higher polyamines spermidine and spermine. Amino Acids 38, 405-413. doi: 10.1007/s00726-009-0 399-4

Medina, C. L., Sanches, M. C., Tucci, M. L., Sousa, C. A., Cuzzuol, G. R., and Joly, C. A. (2009). Erythrina speciosa (Leguminosae-Papilionoideae) under soil water saturation: morphophysiological and growth responses. Ann. Bot. 104, 671-680. doi: 10.1093/aob/mcp159

Mekonnen, D. W., Flugge, U. I., and Ludewig, F. (2016). $\gamma$-aminobutyric acid depletion affects stomata closure and drought tolerance of Arabidopsis thaliana. Plant Sci. 245, 25-34. doi: 10.1016/j.plantsci.2016. 01.005

Mercer, C. F., and Watson, R. N. (2007). Effects of nematicides and plant resistance on white clover performance and seasonal populations of nematodes parasitizing white clover in grazed pasture. J. Nematol. 39, 298-304. Available online at: http://journals.fcla.edu/jon/article/view/67741

Narsai, R., Rocha, M., Geigenberger, P., Whelan, J., and van Dongen, J. T. (2011). Comparative analysis between plant species of transcriptional and metabolic responses to hypoxia. New Phytol. 190, 472-487. doi: 10.1111/j.1469-8137.2010.03589.x

Nayyar, H., Kaur, R., Kaur, S., and Singh, R. (2013). $\gamma$-aminobutyric acid (GABA) imparts partial protection from heat stress injury to rice seedlings by improving leaf turgor and upregulating osmoprotectants and antioxidants. J. Plant Growth Regul. 33, 408-419. doi: 10.1007/s00344-013-9 389-6

Parida, A. K., Dagaonkar, V. S., Phalak, M. S., and Aurangabadkar, L. P. (2008). Differential responses of the enzymes involved in proline biosynthesis and degradation in drought tolerant and sensitive cotton genotypes during drought stress and recovery. Acta Physiol. Plant. 30, 619-627. doi: 10.1007/s11738-008-0157-3

Ramesh, S. A., Tyerman, S. D., Gilliham, M., and Xu, B. (2017). $\gamma$ aminobutyric acid (GABA) signalling in plants. Cell. Mol. Life Sci. 74, 1-27. doi: 10.1007/s00018-016-2415-7

Rangan, P., Subramani, R., Kumar, R., Singh, A. K., and Singh, R. (2014). Recent advances in polyamine metabolism and abiotic stress tolerance. Biomed. Res. Int. 2014:239621. doi: 10.1155/2014/239621

Rena, A. B., and Splittstoesser, W. E. (1975). Proline dehydrogenase and pyrroline-5-carboxylate reductase from pumpkin cotyledons. Phytochemistry 14, 657-661. doi: 10.1016/0031-9422(75)83010-X

Renault, H., Roussel, V., El Amrani, A., Arzel, M., Renault, D., Bouchereau, A., et al. (2010). The Arabidopsis pop2-1 mutant reveals the involvement of GABA transaminase in salt stress tolerance. BMC Plant Biol. 10:20. doi: 10.1186/1471-2229-10-20

Rentsch, D. (1998). Amino acid transport in plants. Trends Plant Sci. 3, 188-195. doi: 10.1016/S1360-1385(98)01231-X

Roussos, P. A., and Pontikis, C. A. (2007). Changes of free, soluble conjugated and bound polyamine titers of jojoba explants under sodium chloride salinity in vitro. J. Plant Physiol. 164, 895-903. doi: 10.1016/j.jplph.2006. 05.003

Sequera-Mutiozabal, M., Tiburcio, A. F., and Alcázar, R. (2016). Drought stress tolerance in relation to polyamine metabolism in plants. Drought Stress Tol. Plants 1, 267-286. doi: 10.1007/978-3-319-28899-4_11

Serraj, R., Shelp, B. J., and Sinclair, T. R. (1998). Accumulation of $\gamma$-aminobutyric acid in nodulated soybean in response to drought stress. Physiol. Plant. 102, 79-86. doi: 10.1034/j.1399-3054.1998.1020111.x

Shang, H., Cao, S., Yang, Z., Cai, Y., and Zheng, Y. (2011). Effect of exogenous $\gamma$-aminobutyric acid treatment on proline accumulation and chilling injury in peach fruit after long-term cold storage. J. Agric. Food Chem. 59, 1264-1268. doi: $10.1021 /$ jf104424z

Sharma, S., Villamor, J. G., and Verslues, P. E. (2011). Essential role of tissuespecific proline synthesis and catabolism in growth and redox balance at low water potential. Plant Physiol. 157, 292-304. doi: 10.1104/pp.111.183210

Shi, S. Q., Shi, Z., Jiang, Z. P., Qi, L. W., Sun, X. M., Li, C. X., et al. (2010). Effects of exogenous $\mathrm{GABA}$ on gene expression of Caragana intermedia roots under $\mathrm{NaCl}$ stress: regulatory roles for $\mathrm{H}_{2} \mathrm{O}_{2}$ and ethylene production. Plant Cell Environ. 33, 149-162. doi: 10.1111/j.1365-3040.2009.02065.x

Signorelli, S., Coitiño, E. L., Borsani, O., and Monza, J. (2014). Molecular mechanisms for the reaction between ( ) OH radicals and proline: insights on the role as reactive oxygen species scavenger in plant stress. J. Phys. Chem. B 118, 37-47. doi: 10.1021/jp407773u

Smirnoff, N., and Cumbes, Q. J. (1989). Hydroxyl radical scavenging activity of compatible solutes. Phytochemistry 28, 1057-1060. doi: 10.1016/0031-9422(89)80182-7

Steward, F. C., Thompson, J. F., and Dent, C. E. (1949). $\gamma$-aminobutyric acid: a constituent of the potato tuber? Science 110, 439-440.

Su, G., An, Z., Zhang, W., and Liu, Y. (2005). Light promotes the synthesis of lignin through the production of $\mathrm{H}_{2} \mathrm{O}_{2}$ mediated by diamine oxidases in soybean hypocotyls. J. Plant Physiol. 162, 1297-1303. doi: 10.1016/j.jplph.2005. 04.033

Trovato, M., Mattioli, R., and Costantino, P. (2008). Multiple roles of proline in plant stress tolerance and development. Rendiconti Lincei 19, 325-346. doi: 10.1007/s12210-008-0022-8

Vijayakumari, K., and Puthur, J. T. (2015). $\gamma$-Aminobutyric acid (GABA) priming enhances the osmotic stress tolerance in Piper nigrum Linn. plants subjected to PEG-induced stress. Plant Growth Regul. 78, 57-67. doi: 10.1007/s10725-015-0074-6

Wang, C., Fan, L., Gao, H., Wu, X., Li, J., Lv, G., et al. (2014). Polyamine biosynthesis and degradation are modulated by exogenous $\gamma$-aminobutyric acid in root-zone hypoxia-stressed melon roots. Plant Physiol. Biochem. 82, 17-26. doi: 10.1016/j.plaphy.2014.04.018

Williams, I., and Frank, L. (1975). Improved chemical synthesis and enzymatic assay of delta-1-pyrroline-5-carboxylic acid. Anal. Biochem. 64, 85-97. doi: 10.1016/0003-2697(75)90408-X

Xiang, L., Hu, L., Xu, W., Zhen, A., Zhang, L., and Hu, X. (2016). Exogenous $\gamma$-aminobutyric acid improves the structure and function 
of photosystem II in muskmelon seedlings exposed to salinityalkalinity stress. PLoS ONE 11:e0164847. doi: 10.1371/journal.pone.01 64847

Yamaguchi, K., Takahashi, Y., Berberich, T., Imai, A., Takahashi, T., Michael, A. J., et al. (2007). A protective role for the polyamine spermine against drought stress in Arabidopsis. Biochem. Biophys. Res. Commun. 352, 486-490. doi: 10.1016/j.bbrc.2006.11.041

Yang, R., Guo, Q., and Gu, Z. (2013). GABA shunt and polyamine degradation pathway on $\gamma$-aminobutyric acid accumulation in germinating fava bean (Vicia faba L.) under hypoxia. Food Chem. 136, 152-159. doi: $10.1016 /$ j.foodchem.2012.08.008
Conflict of Interest Statement: The authors declare that the research was conducted in the absence of any commercial or financial relationships that could be construed as a potential conflict of interest.

Copyright $\odot 2017$ Yong, Xie, Li, Li, Zhang, Nie, Zhang, Ma, Huang, Yan and Peng. This is an open-access article distributed under the terms of the Creative Commons Attribution License (CC BY). The use, distribution or reproduction in other forums is permitted, provided the original author(s) or licensor are credited and that the original publication in this journal is cited, in accordance with accepted academic practice. No use, distribution or reproduction is permitted which does not comply with these terms. 